\title{
Gynecological disorders in geriatric women regarding their frequency, diagnosis and management in the state of Himachal Pradesh, India
}

\author{
Nishi Sood*, Parul Chandra, Bishan Dhiman
}

Department of Obstetrics and Gynecology, Indira Gandhi Medical College, Shimla, Himachal Pradesh, India

Received: 07 November 2017

Accepted: 02 December 2017

*Correspondence:

Dr. Nishi Sood,

E-mail: nishi5644@gmail.com

Copyright: (C) the author(s), publisher and licensee Medip Academy. This is an open-access article distributed under the terms of the Creative Commons Attribution Non-Commercial License, which permits unrestricted non-commercial use, distribution, and reproduction in any medium, provided the original work is properly cited.

\begin{abstract}
Background: Geriatric gynaecological problems have not received adequate attention in India. This study was undertaken to assess gynaecological disorders in geriatric women regarding their frequency, diagnosis and management in Himachal Pradesh, India.

Methods: It was a prospective observational study of patients aged above 60 years, admitted in Gynecology ward, IGMC Shimla over one year. Spectrum of gynecological disorder, comorbidities, diagnosis and management were noted and analyzed.

Results: 224 patients aged 60 years and above were admitted over a period of one year. The commonest presenting complaint was postmenopausal bleeding in $41.07 \%$ of patients. $80.80 \%$ patients had one or more comorbid conditions. Malignancy was the most frequent diagnosis $54 \%$ followed by uterovaginal prolapse in $30.35 \%$. Ovarian cancer constituted $47.93 \%$ followed by cervical cancer $31.40 \% .89 .65 \%$ patients of ovarian cancer had surgical treatment whereas only $21.05 \%$ of cervical cancer patients underwent surgical treatment and rest were referred for radiation. In 62 out of 68 cases of pelvic organ prolapse had definitive surgical treatment.

Conclusions: Pelvic organ prolapse and genital malignancy are the major gynecological causes of hospital admissions in the patients above 60 years. Ovarian and endometrial cancer are showing a rising trend in this age group. Cervical cancer was the second most common malignancy in this group and most of these patients presented at advanced stage. Therefore, recommendations to discontinue screening in older age groups must be viewed with caution.
\end{abstract}

Keywords: Geriatric women, Genital malignancy, Gynecological disorders, Ovarian and endometrial cancer

\section{INTRODUCTION}

The word Geriatrics was coined by Dr. Ignatz Natcher an Austrian physician in 1909. However, it was in 1935 that a British doctor Marjory Warren, working in USA first developed the practical concept of geriatric rehabilitation. With her initiation the elderly patients were gradually taken over by teaching hospitals. ${ }^{1}$

Many studies from developed countries defined older persons as those aged more than 65 years, whereas some use the cut off of $60 \mathrm{yrs}$. Life expectancy of India is 61 years as compared to 72 to 82 years in the developed countries. Thus, the cutoff of 65 years may not be appropriate in Indian context and therefore a lower cut off of greater than and equal to 60 years is used. ${ }^{2}$

A major challenge for the world in the $21^{\text {st }}$ century is the ageing of its population ${ }^{2}$. The world's elderly population is growing at a rate of $2.4 \%$ per year. The age shift is the result of reduced birth rates, improvement in health and nutrition and increased longevity. The aging population 
has a direct effect on health- care delivery because it is associated with a new disease patterns as well as transitions in economic,social and even ethical issues. ${ }^{3}$

The Indian society which was pyramidal till $20^{\text {th }}$ century, has become rectangular today and morbidity related to geriatric gynaecological problems is on the rise. ${ }^{4}$ In India the number of people aged more than 60 years has grown from $5.4 \%$ in 1951 to $8.4 \%$ in 2011 and is projected to become $12.5 \%$ by 2025 . As per the census of 2011 , whereas for total Indian population, sex ratio is in favor of male population in ratio 940:1000, however for elderlies at sixty years and above population it is in favour of elderly women by 1022:1000. There are 50.33 million elderly women in India as per 2011 census. ${ }^{5}$

Gynaecological disorders in older women differ from those who are younger. Elderly women experience vasomotor, urogenital, psychosomatic, psychological symptoms and sexual dysfunction. These urogenital changes make women vulnerable to gynaecological morbidities. Common gynaecological problems encountered in elderly women are vulvovaginal inflammation, genital prolapse, postmenopausal bleeding, malignancy and alteration in bladder function. ${ }^{6}$

The risk of developing Gynecologic tumor is highest in geriatric women when compared with women aged up to 60 years. Those over the age of 65 have a higher risk of developing cancer of the uterus (two fold), ovaries (three fold) and Cervix (10\% increased risk) ${ }^{7}$. There is also an increased risk of cancer related death in geriatric women that seems to be independent of increased incidence. One possible explanation is related to stage of disease as Ovarian, Endometrial and Cervical cancers tend to be diagnosed at a more advanced stage in elderly women. ${ }^{3}$

Population aging is emerging as a pre-eminent phenomenon throughout the world. Among the aged, the women deserve special attention because they outlive men in most societies. Nevertheless, postmenopausal and geriatric gynaecological problems have not received adequate attention in India. There is an obvious need of screening programme for early detection of gynecological malignancy to provide better geriatric services, but a paucity of data regarding gynaecological morbidity in geriatric women hampers proper planning. ${ }^{8}$

Hence the present study was contemplated with view to assess the magnitude of gynaecological morbidity in the state of Himachal Pradesh to help in early diagnosis and treatment. The Geriatric care can best be summed up by the slogan of the British Geriatric society "Adding Life to Years". 1

This study was conducted in the Department of Obstetrics and Gynecology at Kamla Nehru Hospital for mother and Child at IGMC, Shimla. (H.P) which is premier medical college of the state catering to both urban and rural population.

\section{METHODS}

It was a prospective observational study done over one year period. All elderly women admitted in our institution aged 60 years and above were included in the study. Ethical clearance was obtained from the ethical committee of the institution.

Detailed history, including history related to menopause, personal history and medical history was recorded. Gynecological examination was done including Papanicolaou smear (Pap smear). Routine investigations included a complete haemogram, blood biochemistry, urine examination and pelvic ultrasonography.

Probable diagnosis of gynecological disorders was made and if any special investigations were required, they were done accordingly. Fractional curettage and cervical biopsy if indicated was taken and tissue sent for histopathological examination (HPE) in the Pathology Department of I.G.M.C Shimla. Cancers markers if required were also advised. Any other special investigations like Computed tomography scan and Magnetic resonance imaging if required were advised.

After definitive diagnosis of gynecological disorders, the treatment was started accordingly. All data collected was recorded and analyzed statistically.

\section{RESULTS}

In our study there were 224 patients aged 60 years and above, amongst total admission of 3014 in the Gynaecology ward. The incidence of hospital admission of geriatric female patient came out to be $7.43 \%$.

Table 1: Age distribution of elderly women (study population) $(n=224)$.

\begin{tabular}{|lll|} 
Age (in years) & Number & Incidence \% \\
\hline $60-65$ & 117 & 52.23 \\
\hline $65-70$ & 60 & 26.78 \\
\hline $70-75$ & 33 & 14.73 \\
\hline 75 & 14 & 6.25 \\
\hline
\end{tabular}

As shown in Table 1, $117(52.23 \%)$ were in the age group of 60-65 years, $60(26.78 \%)$ in the age group of $66-70$ years, $33(14.73 \%)$ in the age group of $71-75$ years and $14(6.25 \%)$ were more than $75 y$ years.

Mean parity in the admitted patients was four. 55 patients $(24.55 \%)$ out of the 224 were smokers. The average age of menopause was 45 years and 210 patients (94.15\%) had natural menopause whereas 14 patients $(6.25 \%)$ gave history of surgical menopause. Of these 14 patients, 11 had undergone total abdominal hysterectomy with or without salpingo oopherectomy whereas 3 patients had undergone vaginal hysterectomy. 
Table 2: Incidence of gynecological symptoms in the study subjects.

\begin{tabular}{|lll|}
\hline Gynecological symptoms & No. & Incidence \% \\
\hline Post menopausal bleeding & 92 & 41.07 \\
\hline Pain abdomen and distension & 84 & 37.50 \\
\hline $\begin{array}{l}\text { Something coming out of } \\
\text { introitus }\end{array}$ & 68 & 30.35 \\
\hline Discharge per vaginum & 36 & 16.07 \\
\hline Urinary symptoms & 16 & 7.14 \\
\hline Women with single symptom & 98 & 43.75 \\
\hline $\begin{array}{l}\text { Women with multiple } \\
\text { symptoms }\end{array}$ & 126 & 56.25 \\
\hline
\end{tabular}

As can be seen from Table 2 the most common presenting complaint was postmenopausal bleeding in 92 patients $(41.07 \%)$, followed by pain and abdominal distention in 84 patients $(37.50 \%) .68$ patients $(30.35 \%)$ complained of something coming out of introitus, 36 patients $(16 \%)$ reported discharge per vaginum and 16 patients $(7.14 \%)$ had urinary complaints. 98 females had single complaint while 126 patients had more than one complaint.

Table 3: Associated co morbidities in geriatric women (n-181).

\begin{tabular}{|lll|}
\hline Disease & Number & Incidence \% \\
\hline Hypertension & 132 & 72.92 \\
\hline COPD & 30 & 16.57 \\
\hline Hypothyroidism & 24 & 13.25 \\
\hline Diabetes Mellitus & 22 & 12.15 \\
\hline Anemia & 19 & 10.49 \\
\hline Coronary Artery Disease & 15 & 8.28 \\
\hline $\begin{array}{l}\text { Others (DVT, CKD, Liver } \\
\text { disease) }\end{array}$ & 5 & 2.76 \\
\hline
\end{tabular}

181 patients had one or more comorbid conditions (Table 3). Hypertension $(72.92 \%)$ was the most common followed by chronic obstructive pulmonary disease (16.57\%), hypothyroidism (13.25\%), diabetes mellitus $(12.15 \%)$, anemia $(10.49 \%)$, coronary artery disease $(8.28 \%)$ and other diseases like chronic kidney disease, deep vein thrombosis and liver disease which constituted $2.76 \%$ of the cases.

Table 4: Spectrum of gynaecological disorders in elderly women $(n=224)$.

\begin{tabular}{|lll|}
\hline Disease & No. & Overall Incidence \% \\
\hline Malignancies & 121 & 54.01 \\
\hline Uterovaginal prolapse & 68 & 30.35 \\
\hline Benign Ovarian lesion & 19 & 8.40 \\
\hline Urinary incontinence & 16 & 7.14 \\
\hline
\end{tabular}

Malignancy was the most frequent diagnosis with 121 $(54.01 \%)$ patients having malignant disease followed by uterovaginal prolapse, ovarian cyst and urinary complaints (Table 4).
Table 5: Gynaecological cancers in geriatric women (n-121).

\begin{tabular}{|lll|}
\hline Type of cancer & Number & Incidence \% \\
\hline Ovarian CA & 58 & 47.93 \\
\hline Cervical CA & 38 & 31.40 \\
\hline Endometrial CA & 15 & 12.39 \\
\hline Vulval CA & 8 & 6.61 \\
\hline Vaginal CA & 2 & 1.65 \\
\hline
\end{tabular}

Of the total malignancies (Table 5), ovarian cancer constituted $47.93 \%(\mathrm{n}=58)$ followed by cervical cancer $31.40 \%$ (n 38) endometrial carcinoma $12.39 \% \quad(n=15)$, vulval cancer $6.61 \%(\mathrm{n}=8)$ and vaginal cancer $1.65 \%$ $(n=2)$.

68 patients had uterovaginal prolapse of which 37 patients had third degree prolapse, 21 patients had second degree prolapse, 6 patients had vault prolapse post hysterectomy and 4 patients had procidentia.

Benign ovarian cyst was seen in 19 patients while 16 patients had urinary incontinence.

Type 6: Types of surgeries performed in gynecological disorders.

\begin{tabular}{|l|l|l|}
\hline Type of surgery & Number & Incidence (\%) \\
\hline VH with PFR & 56 & 25 \\
\hline TAH with BSO & 52 & 23.21 \\
\hline Extrafascial hysterectomy & 17 & 7.5 \\
\hline B/L Salpingo ooprectomy & 5 & 2.2 \\
\hline Wertheim's hysterectomy & 6 & 2.6 \\
\hline $\begin{array}{l}\text { Sacrospinous colpopexy } \\
\text { with cystocele repair }\end{array}$ & 6 & 2.6 \\
\hline Pyometra & 22 & 9.8 \\
\hline Fractional curettage & 36 & 16 \\
\hline Cervical Bx & 14 & 6.2 \\
\hline Hysteroscopic Bx & 3 & 1.3 \\
\hline $\begin{array}{l}\text { Vulvectomy with inguinal } \\
\text { lymphadenectomy }\end{array}$ & 2 & 0.89 \\
\hline Pessary & 3 & 1.3 \\
\hline Burch colposuspension & 2 & 0.89 \\
\hline
\end{tabular}

Table 6 and Table 7 shows that in 52 patients of ovarian cancer, exploratory laparotomy proceed total abdominal hysterectomy with bilateral salpingo oopherectomy with infracolic omentectomy with surgical staging of tumour was done. Five patients were sent for neoadjuvant chemotherapy and one patient with Krukenberg tumor with cancer breast was referred to department of surgery for further management.

Six out of 38 patients diagnosed with cervical cancer underwent Wertheim's hysterectomy while two had extrafascial hysterectomy and rest reported with advanced stage disease and were referred for radiation therapy. Extrafascial hysterectomy with pelvic 
lymphadectomy was done in all 15 patients of endometrial carcinoma.

Table 7: Treatment modalities in different type of malignancies.

\begin{tabular}{|lll|}
\hline $\begin{array}{l}\text { Type of } \\
\text { malignancy } \\
\text { n-121 }\end{array}$ & $\begin{array}{l}\text { Treatment given } \\
\text { Ovarian } \\
\text { cancer, n-58 }\end{array}$ & $\begin{array}{l}\text { TAH with BSO with } \\
\text { patients }\end{array}$ \\
\hline $\begin{array}{l}\text { Infracolic omentectomy } \\
\text { Neo adjuvant } \\
\text { chemotherapy }\end{array}$ & 52 \\
\hline $\begin{array}{l}\text { Cervical } \\
\text { cancer, n-38 }\end{array}$ & $\begin{array}{l}\text { Werthiems hysterectomy } \\
\text { Extrafascial hysterctomy }\end{array}$ & 6 \\
\hline $\begin{array}{l}\text { Endometrial } \\
\text { cancer, n-15 }\end{array}$ & $\begin{array}{l}\text { Extrafascial hysterctomy } \\
\text { with pelvic } \\
\text { lymphadenectomy }\end{array}$ & 30 \\
\hline $\begin{array}{l}\text { Vulval cancer } \\
\text { n-8 }\end{array}$ & $\begin{array}{l}\text { Vulvectomy with } \\
\text { inguinal } \\
\text { lymphadenectomy }\end{array}$ & 15 \\
\hline
\end{tabular}

In 56 cases of pelvic organ prolapse, vaginal hysterectomy with pelvic floor repair was done whereas in 6 cases of vault prolapse sacrospinous colpopexy with cystocele repair was done and three patients had pessary insertion. 36 patients had fractional curettage which was combined with cervical biopsy in 14 patients for postmenopausal bleeding. Drainage of pyometra was done in 22 cases and hystereroscopic guided endometrial biosy was done in 3 patients. Simple vulvectomy with inguinal lymphadenectomy and Burch colposuspension was done in two patients each.

\section{DISCUSSION}

In our study the commonest age group in patients who were admitted for gynecological complaint was between 60-65year and it was $52.23 \%$. This is consistent with the study done by Dey et al in which $45.56 \%$ of the patients admitted in ward above 60 years were in the age group of 60-65 years. ${ }^{4}$ The average age of menopause was 45 years which is also consistent with Pan Indian study done by Ahuja $\mathrm{M}$ who reported average age of menopause in northern India to be $45+3$ years. ${ }^{9}$ The natural menopausal age of a woman serves as a biomarker for subsequent disease prediction and mortality. ${ }^{10}$ Epidemiological studies have identified that age adjusted mortality is reduced by $2 \%$ while the risk of uterine/ovarian cancer increases by $5 \%$ with each increasing year of age at menopause. $^{11}$

In $6.2 \%$ of patients menopause was secondary to hysterectomy which is much lower than that reported by MerrillRM12 which was as high as $33 \%$ by the age of 55 years in some of the American states. In our study the most common presenting complaint was postmenopausal bleeding (41.07\%) and the commonest diagnosis was genital malignancy $(54.01 \%)$ followed by uterovaginal prolapse (30.35\%). The risk of developing a gynecological cancer is highest in elderly women. ${ }^{7}$ In present study the incidence of genital malignancy was much higher than that reported by other Indian studies. ${ }^{2,4,8}$

Among the gynaecological malignancies (121 patients), ovarian carcinoma was the most common (47.93\%) followed by cervical carcinoma $(31.40 \%)$. This is consistent with the trend increasingly reported from india in which ovarian and corpus uteri malignancies are on the rise in the past two decades. ${ }^{13}$ Cancer cervix is the second commonest magnancy seen in females after cancer Breast in India. ${ }^{14-16}$

In present study incidence of cervical cancer seems to be less. This may be because the incidence of invasive cervical cancer is lower in women aged 65 and over, but mortality is higher, largely because stage at the time of diagnosis is more advanced. ${ }^{17}$

A review of cancer deaths in women in Australia aged 50 and above found that $70 \%$ could have been avoided by appropriate screening. In the women aged 50 to $74,67 \%$ had never been screened, and none of those aged 75 and over had had a Papsmear. ${ }^{18}$ This has been corraborated by studies in United States that because of decreased medical office visits there is late stage diagnosis of cancer cervix in the elderly. ${ }^{19}$

Pelvic organ prolapse is a major cause of hospital admissions and surgery in geriatric women. In our study $30.35 \%$ of elderly patients had Pelvic organ prolapse. The incidence of pelvic organ prolapse is lower in current study than that seen in the study done by Dey et al who reported an incidence of $51.1 \%{ }^{4}$ Similarly in a study done by Swift et al in older patients receiving routine gynecologic care, the incidence of pelvic organ prolapse reported was much higher as compared to our study. ${ }^{20}$

In this study $50 \%$ to $60 \%$ were found to have stage II POP; stage III prolapse was present in $9 \%$ of the women aged 60 to 69 and $21 \%$ of the women aged 70 and over. Age was found to be an independent risk factor for symptomatic pelvic floor dysfunction (including POP) in a large Australian household survey. ${ }^{21}$ Other risk factors that have been identified are parity, body mass index, chronic lung disease and coughing. ${ }^{21-23}$ This was consistent with findings in our study where apart from advanced age and high parity (commonest parity being 4 and above), high prevalence of smoking (24.54\%) was seen in geriatric age group.

Out of 68 admitted patients with pelvic organ prolapse, 62 patients had definitve surgery including vaginal hysterectomy with pelvic floor repair, repair of cystocele, enterocele and sacrospinous colpopexy. 6 patients had conservative management including pessary insertion for 3 patients. $89.65 \%$ (n 52) of patients with ovarian cancer had total abdominal hysterectomy with salpingo- 
oopherectomy with infracolic omentectomy with surgical staging of tumor, five patients were sent for neoadjuvant chemotherapy and one patient with Krukenberg tumor with cancer breast was reffered to deptt of surgery for further management. All cancer endometrium patients had extrafascial hysterectomy with pelvic lymphadenectomy for. But only eight out of 38 cancer cervix patients could be operated because of advanced stage of disease which is consistent with the fact that cervical cancer is seen in advanced stages in elderly patients. ${ }^{17}$ Wertheims hysterectomy was done in 6 patients and extrafascial hysterectomy in 2 patients with cancer cervix. Rest of the patients received radiation. This is consistent with the study done by Ying Gao et al where radiotherapy was the most frequent treatment given to geriatric patients in cancer cervix. ${ }^{24}$ Two patients of stress urinary incontinence were treated surgically with Burch Colposuspension whereas rest were managed conservatively.

\section{CONCLUSION}

Pelvic organ prolapse and genital malignancy are the major gynaecological causes of hospital admissions in the patients above 60 years. Post menopausal bleeding is the commonest complaint. Ovarian and endometrial cancer are showing a rising trend in this age group. Though cervical cancer was the second most common malignancy in this group, most of these patients presented at advanced stage and hence were inoperable. Therefore, recommendations to discontinue screening in older age groups must be viewed with caution. Reluctance to undergo pelvic examination in this group must be sensitively addressed so that increased morbidity due to delay in diagnosis is avoided. With $80.80 \%$ of these patients having comorbidites, these patients are at high risk for surgery. Therefore, there should be separate operation theater units to handle this fragile subset of population.

\section{Funding: No funding sources}

Conflict of interest: None declared

Ethical approval: The study was approved by the Institutional Ethics Committee

\section{REFERENCES}

1. Barton A, Mulley G.History of the development of geriatric medicine in the UK. Postgraduate Med J. 2003;79:229-34.

2. Takkar N, Goel P, Dua D, Mohan H, Huria A, Sehgal A. Spectrum of gynecological disorders in older Indian women: a hospital based study. Asian J Gerontol Geriatr. 2010;5:69-73.

3. Ramin M, Wilberto N, Hervy AE. Gynaecological malignancy in older women. Oncology. 2001;5.

4. Dey R, Saha MM, Rakshit A, Biswas SC, Mukhopadhyay A. The epidemiology of gynaecological disorders in geriatric population: a hospital based study. J Evol Med Dental Sci. 2013;14:23-9.

5. Census of India 2011. Available at http//www.censusindia.gov.in/census_data_2011. Accessed 13 june 2016.

6. Scott RB. Common problems in geriatric gynecology. Am J Nursing. 1958;58:1275-7.

7. US National Institutes of Health. Cancer of the cervix uteri. 2005. Available at: http://www.cancer.gov. Accessed on March 20, 2013.

8. Susila T, Roy G. Gynecological morbidities in a population of rural postmenopausal women in pondicherry: uncovering the hidden base of the Iceberg. J Obstet Gynecol India. 2014;64(1):53-8.

9. Ahuja M. Age of menopause and determinants of menopause age: A PAN India survey by IMS, Available at http://www.jmidlifehealth.org Accessed on 27.10 .2017

10. Cooper GS, Sandler DP. Age at natural menopause and mortality. Ann Epidemiol. 1998;8:229-35.

11. Ossewaarde ME, Bots ML, Verbeek AL, Peeters PH, van der Graaf Y, Grobbee DE, et al. Age at menopause, cause-specific mortality and total life expectancy. Epidemiology. 2005;16:556-62.

12. Merrill RM. Prevalence corrected hysterectomy rates and probabilities in Utah. Ann Epidemiol. 2001;11:127-135.

13. Yeole BB. Trends in cancer incidence in female breast, cervix uteri, corpus uteri, and ovary in India. Asian Pac J Cancer Prev. 2008;9:119-22.

14. Ferlay J, Soerjomataram I, Ervik M. GLOBOCAN 2012 v1.0, Cancer Incidence and Mortality Worldwide: IARC Cancer Base No. 11 [Internet]. Lyon, France: International Agency for Research on Cancer; 2013.

15. Bray F, Ren JS, Masuyer E, Ferlay J. Estimates of global cancer prevalence for 27 sites in the adult population in 2008. Int J Cancer. 2013;132(5):113345.

16. Guidelines for Cervical Cancer Screening Programme. Available at http://screening.iarc.fr/doc/WHO_India_CCSP_guid elines_2005.

17. Wright TC, Ferenczy A, Kurman RJ. Carcinoma and other tumors of the cervix. In Kurman RJ (ed): Blaustein's Pathology of the Female Genital Tract, 4th ed. New York: Springer-Verlag;1994:279-326.

18. Mitchell H, Medley G, Higgins V. An audit of the women who died during 1994 from cancer of the cervix in Victoria, Australia. Aust N Z J Obstet Gynecol. 1996;36:73-6.

19. Ferrante JM, Gonzale EC, Roetzheim RG, Pal N, Woodard L. Clinical and demographic predictors of late stage cervical cancer. Arch Fam Med. 2000;9:439-45.

20. Swift SE. The distribution of pelvic organ support in a population of female subjects seen for routine gynecologic health care. Am J Obstet Gynecol. 2000;183:277-285. 
21. MacLennan AH, Taylor AW, Wilson DH, Wilson D. The Prevalance of pelvic floor disorders and their relationship to gender, Age, Parity and mode of delivery. BJOG. 2000;107:1460-70.

22. Olsen AL, Smith VJ, Bergstrom JO, Colling JC, Clark AL. Epidemiology of surgically managed pelvic organ prolapse and urinary incontinence. Obstet Gynecol 1997;89:501-6.

23. Chiaffarino F, Chatenoud L, Dindelli M, Meschia M, Buonaguidi A, Amicarelli F et al. Reproductive factors, family history, occupation and risk of urogenital prolapse. Eur J Obstet Gynecol Reprod Biol. 1999;82:63-7.

24. Gao Y, Ma JL, Gao F, Song LP. The evaluation of older patients with cervical cancer. Clin Interventions Aging. 2013;8:783-8.

Cite this article as: Sood N, Chandra P, Dhiman B. Gynecological disorders in geriatric women regarding their frequency, diagnosis and management in the state of Himachal Pradesh, India. Int J Reprod Contracept Obstet Gynecol 2018;7:297-302. 